\title{
Functional specialization and phenotypic generalization in the pollination system of an epiphytic cactus
}

\section{Cristiane Martins $^{1 *}$ (1) and Leandro Freitas ${ }^{2}$ (1)}

Received: September 22, 2017

Accepted: February 19, 2018

\begin{abstract}
Plant-pollinator interactions range from obligatory specialists to facultative generalists, and floral morphology and pollination system may not match completely. The floral biology, reproductive system and floral visitors of a species of the tribe Rhipsalideae were investigated with a focus on the consistency between the pollination system and the floral phenotype. Rhipsalis neves-armondii is an obligate xenogamous species, due to self-sterility. Its flowers are white, small and diurnal, and radially symmetrical. These features, along with their small amount of nectar, characterize the flowers as phenotypic generalists. The most frequent pollinators were a solitary oligolectic species of Andrenidae (Rhophitulus solani), two species of Meliponinae (Trigona spinipes and T. braueri) and Apis mellifera. Despite the generalist floral phenotype, the pollination system is functionally specialized, since only small bees performed effective visits. Flowers of $R$. neves-armondii may represent a case of cryptic floral specialization in which attributes other than morphology act as filters, restricting them to a single functional group of pollinators. Moreover, the four most frequent species of pollinators cover a spectrum ranging from solitary oligolectic to social polylectic bees, including an exotic species. These results illustrate the distinct dimensions of specialization-generalization that may occur in the pollination process of a single species.
\end{abstract}

Keywords: Cactaceae, floral biology, montane rain forest, oligolectic bees, pollinators, reproductive system, Rhipsalis, self-incompatibility

\section{Introduction}

The interactions between plants and pollinators are one of the most frequent associations in nature, and are highly important in structuring populations, communities and ecosystems (Ollerton 2006; Sargent \& Ackerly 2008). Mutualism between these two groups of organisms is based on a condition of mutual exploitation, in which the animals acquire food or some other resource, while the plants obtain effective vectors for their sexual reproduction (Nicolson \& Wright 2017). In this relationship, factors such as the efficacy and frequency of visitation of pollinators, together with the morphological attributes of both species influence the plant's reproductive success (Stebbins 1970; Ne'eman et al. 2010; Freitas 2013; King et al. 2013). Assessment of the morphological adjustment between flowers and pollinators is important in evaluating plant-pollinator interactions (Anderson et al. 2010). This perspective is related to the concept of pollination syndromes, which establishes that sets of floral attributes, such as shape, color, size, odor and resources, reflect the specific group of pollinators. Thus, certain flower characteristics are expected to be adaptive responses to the pressures exerted by the respective group

1 Programa de Pós-Graduação em Ecologia, Universidade Federal do Rio de Janeiro, 21941-971, Rio de Janeiro, RJ, Brazil

2 Jardim Botânico do Rio de Janeiro, 22460-030, Rio de Janeiro, RJ, Brazil

* Corresponding author: cristianemartinsleandro@gmail.com 
of pollinators, leading to convergent floral evolution in unrelated species (Faegri \& Pijl 1979).

The view that pollination systems tend toward specialization, which is implicit in the concept of pollination syndromes, has been challenged after some studies proposing that generalist systems are quite frequent (Waser et al. 1996). This debate has expanded past the initial polarization, to arrive at the understanding that plantpollinator interactions are distributed on a gradient from one extreme of obligate specialists, involving interaction between only two species, to the other extreme of facultative generalists, in which flowers can be appropriately served by a wide range of pollinators (Johnson \& Steiner 2000; Ollerton et al. 2007). Broadly viewed, this categorization refers to the plant niche width, whereby specialist plant species would have narrower pollinating niches than would generalist species (Grant \& Grant 1965; Armbruster 1993; Thomson \& Wilson 2008; Gómez et al. 2014). The concept of specialization of plant-pollinator interactions has been refined to include a variety of parameters from different perspectives (ecological, phenotypic and evolutionary) (e.g. Ollerton et al. 2007). All these proposals are valid, but a clear definition in the context of each study is necessary, because different interpretations of specialization have different evolutionary and ecological implications (Armbruster 2017).

Considering the wide spectrum of degrees of specialization or generalization in the relationships between plants and pollinators, Ollerton et al. (2007) proposed to categorize the specialization-generalization of a plant species in relation to its pollinators in three modalities: (1) functional, which means the diversity of pollinators of a plant at higher taxonomic levels or functional groups (e.g. plants pollinated by bats, resin-bees or hummingbirds); (2) ecological, which means the number of pollinator species that interact with the plant; and (3) phenotypic, which encompasses the floral characters that make the flower potentially more or less restrictive to a pollinator group (e.g. type and accessibility to the floral resource). From this perspective, it is possible to have opposing combinations of these categories, as in cases where phenotypically generalist flowers are functionally specialists and vice versa (Ollerton et al. 2007). Recently, Armbruster (2017) suggested changing the term "functional" to "functional group" to bring more clarity to the classification, since the former term is already used in other fields of study.

Species bearing phenotypically generalist flowers generally have pollination systems with ecological and functional generalization, although they may be specialized in some dimension (e.g. McIntosh 2005; Ollerton et al. 2007; Shuttleworth \& Johnson 2009; Narbona \& Dirzo 2010; Niemirski \& Zych 2011; Bartoš et al. 2015). Little is known about the mechanisms by which phenotypically generalist-plants filter their pollinators (Johnson \& Steiner 2000), and a first step toward understanding these mechanisms is the description of the pollination system and its characterization in terms of phenotypic, ecological and functional group specialization-generalization (Ollerton et al. 2007; Armbruster 2017).

Cactaceae comprises about 1,500 species (Hunt et al. 2006) with a wide range of floral syndromes and pollination systems (Pimienta-Barrios \& Castillo 2002; Mandujano et al. 2010; Schlumpberger 2012). Cacti are zoophilic but are associated with diverse animal groups, such as bees, butterflies, moths, bats, hummingbirds and other birds. Species may be pollinated exclusively or not by each animal group, leading to pollination systems with different degrees of functional-group specialization (Pimienta-Barrios \& Castillo 2002; Mandujano et al. 2010; Schlumpberger 2012). Moreover, most species of Cactaceae are xenogamous, which makes them dependent on pollinators for sexual reproduction (Ross 1981; Boyle 1997; Mandujano et al. 2010).

"Cactus" usually evokes an image of large columnar shrubs with succulent spiny stalks, living in deserts or semiarid environments. However, epiphytic cacti are a prominent component in the physiognomy of certain humid forests in the Neotropics. Epiphytism occurrs in ca. $10 \%$ of the species of Cactaceae and has a strong phylogenetic signal, as it is restricted to Hylocereeae and Rhipsalideae (Barthlott 1983). Knowledge of the pollination biology of epiphytic cacti is sparse, being restricted to anecdotal reports (e.g. Fleming et al. 2009) and to a study on pollination by bats in Weberocereus tunilla (Tschapka et al. 1999). Rhipsalis, the largest epiphytic genus of Cactaceae, has flowers that suggest a generalist pollinating system, since they are small and radial, and their resources (nectar and pollen) are apparently accessible to many types of visitors.

We here described the pollination biology of Rhipsalis neves-armondii and discussed the results from the perspective of the degree of phenotypic, functional and ecological specialization-generalization. Our expectation was that pollination system of $R$. neves-armondii would be functionally and ecologically generalized because of its generalist floral phenotype.

\section{Materials and methods}

\section{Species and area of study}

Rhipsalis is composed of 37 species, of which $86 \%$ are endemic to Brazil (Taylor et al. 2015). The genus includes three phylogenetically well-supported subgenera: Rhipsalis, Erytrorhipsalis and Calamorhipsalis, this last having flowers with the pericarpel visibly immersed in the areola (Calvente et al. 2011b; Calvente 2012). Rhipsalis neves-armondii K.Schum. is an epiphytic (Fig. 1A), occasionally rupiculous species of the subgenus Calamorhipsalis from the Brazilian Atlantic Forest (Taylor et al. 2015). The flowers, although they are the largest of the genus, are less than $2 \mathrm{~cm}$ long (Fig. 1B, C). The fruits are violaceous berries (Fig. 1D), 

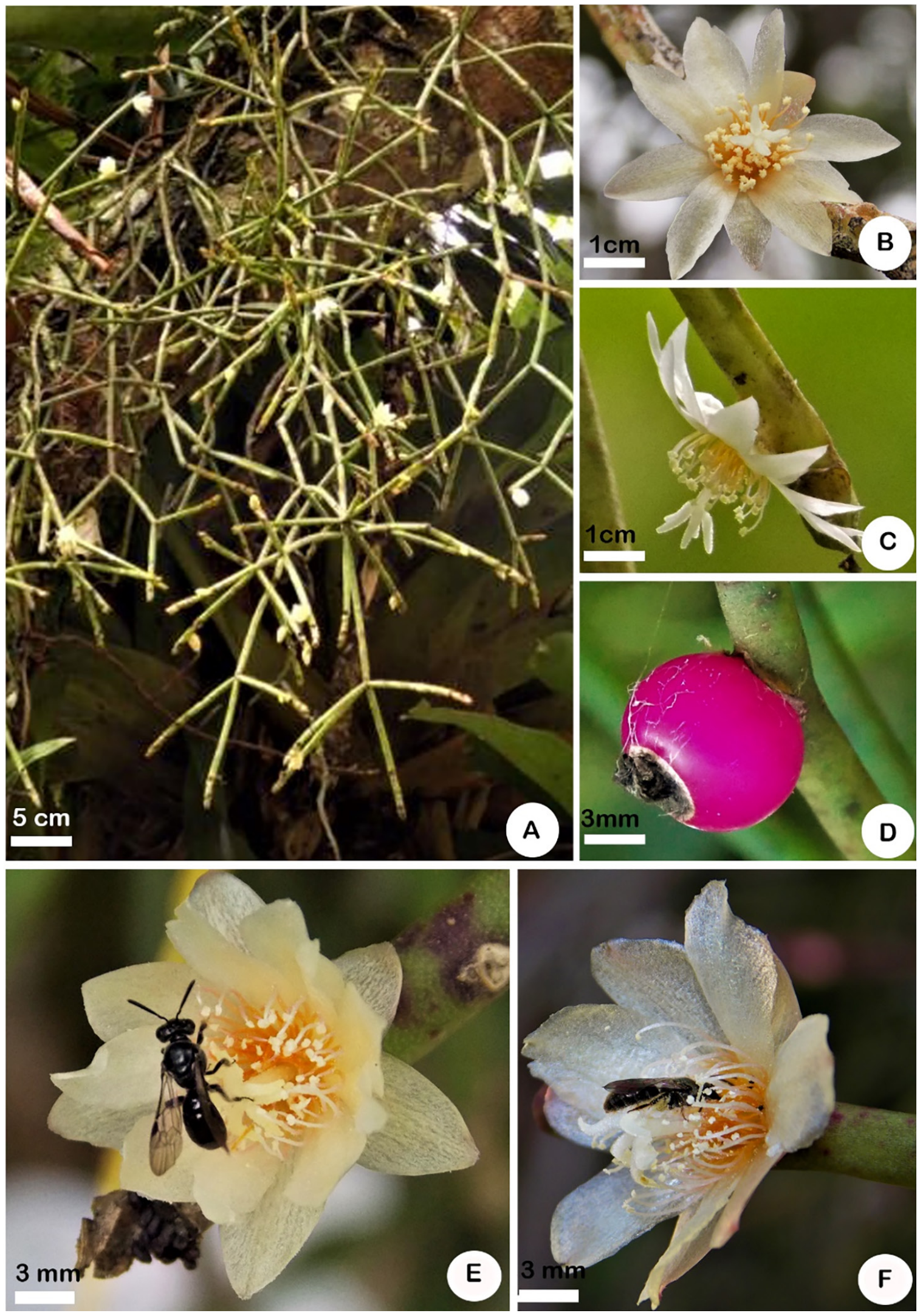

Figure 1. Flowering individual of Rhipsalis neves-armondii in the National Park of Serra dos Órgãos, southeastern Brazil (A). Flower in frontal (B) and side view (C), showing approach herkogamy due to taller stigma. Mature berry fruit (D). Visits to the flower by Rhophitulus solani (Andrenidae), with the bee using the stigma as a landing platform (E) and directing its head toward the base of the flower to take nectar $(\mathbf{F})$. 
which are attractive to birds of various groups that are the likely seed dispersers (Anderson 2001; Schlumpberger et al. 2006). A voucher of $R$. neves-armondii was deposited in the herbarium RB (632076).

The study was carried out in March and April 2014, in a remnant of the Atlantic Forest in the Serra dos Órgãos National Park (PARNASO), southeast Brazil (22 $25^{\circ}-22^{\circ} 32^{\prime} \mathrm{S}$ $42^{\circ} 59^{\prime}-43^{\circ} 07^{\prime} \mathrm{W}$, ca. $1000 \mathrm{~m}$ a.s.l.). PARNASO lies within the area of the Atlantic Forest where the highest species richness of Rhipsalis has been recorded (at least 18 species) (Calvente et al. 2005). The climate is tropical mesothermic with mild summers and a short dry season in the winter months, reflecting the effects of the altitude (Köppen 1936). Flowering occurred at the end of the rainy season, in March and April, and among the ten sympatric species of Rhipsalis in this area, only $R$. neves-armondii was flowering during this period in 2014.

\section{Floral biology}

Corolla diameter and pistil length were measured in 25 flowers from five individuals, in which the number of tepals, stamens and ovules were also counted. The anthesis time and floral longevity were recorded by direct observation of 15 flowers of three individuals. We measured the spectral reflectance of floral structures using a USB2000+UV-VIS spectrometer with a Balanced Deuterium Tungsten Source (DH-2000-BAL, Ocean Optics Inc., Dunedin, FL, USA), calibrated with a standard white $(\mathrm{BaSO} 4)$. The readouts were limited into wavelengths from 300 to $700 \mathrm{~nm}$. The concentration and volume of nectar were measured with a pocket refractometer and microcapillaries $(1 \mu \mathrm{L})$, respectively, in previously bagged flowers in pre-anthesis $(\mathrm{N}=15)$ of five individuals. Nectar was measured at three different times in the same flowers, on the first day of anthesis at 9.00 AM (1) and 3.00 PM (2), and on the second day of anthesis at 9.00 PM (3). Flowers were rebagged after performing each measurement.

\section{Reproductive system}

Four pollination treatments were performed, to identify the reproductive system of $R$. neves-armondii as well as its dependence on animal vectors for seed production. The treatments were: (a) spontaneous self-pollination (n $=30$ ), in which flowers in pre-anthesis were bagged to exclude visitors; (b) manual self-pollination $(\mathrm{n}=25)$, in which flowers were bagged in pre-anthesis, and were then hand-pollinated, using pollen grains from their own anthers; (c) manual cross-pollination ( $\mathrm{n}=14$ ), in which previously bagged flowers were pollinated with pollen grains from flowers of other individuals located at least $10 \mathrm{~m}$ distant; (D) open pollination (natural condition) $(n=28)$, in which flowers were kept open for natural pollination throughout anthesis. Treatments encompassed seven individuals and were conducted between 9.00 and $11.00 \mathrm{AM}$ on the first day of anthesis. After all treatments, flowers were kept bagged until the fruits were ripe. Fruits were collected $45-60 \mathrm{~d}$ after the treatment. We constructed general linear mixed models (GLMM), with binomial error distribution, to evaluate differences in fruit set among pollination treatments. Number of fruits was included as dependent variable, pollination treatments as fixed factor, and mother plant as a random factor. The occurrence of pollen limitation (PL) was evaluated by the index of pollen limitation, expressed by IPL $=1-(\mathrm{Fcn} / \mathrm{Fpc})$, where $\mathrm{Fcn}$ is the percentage of fruiting under natural conditions and $\mathrm{Fpc}$ is the percentage of fruiting after manual cross-pollination (Larson \& Barrett 2000). Negative or near-zero values indicate absence of PL. In addition, the differences in the number of seeds per fruit between the cross-pollination and natural-pollination treatments were analyzed through the general linear mixed models (GLMM), with Poisson error distribution. Number of seeds was included as dependent variable, pollination treatments as fixed factor, and mother plant as a random factor. The statistical analyses were performed in the $\mathrm{R}$ environment.

\section{Flower visitors}

To catalog floral visitors and identify pollinators, focal observations were performed on four individuals at 20-min intervals, between $8.00 \mathrm{AM}$ and $4.00 \mathrm{PM}$, totaling $26 \mathrm{~h}$ of sampling. We recorded information on how the insects approached the flowers, their frequency of visits, which resource was sought, and if they contacted the anthers and stigma. The absolute frequency and the relative frequency of visits were calculated, respectively, by the number of flowers visited / total observation time ( $26 \mathrm{~h}$ ) and by the absolute frequency of the species / total absolute frequency $\mathrm{x} 100$ (Freitas \& Andrich 2013). Floral visitors were classified as pollinators if they contacted the stamens and stigma during visits. Pollinators were captured directly from the flower and preserved for later identification, except Apis mellifera individuals.

\section{Results}

\section{Floral biology}

Flowers of R. neves-armondii are lateral to subterminal, with radial symmetry and measured $1.98 \pm 0.18 \mathrm{~cm}$ in diameter (mean \pm SD throughout the text). The number of perianth elements (tepals) per flower was $12.12 \pm 1.56$, and they are patent, free and white. Approximately 100 stamens $(83.88 \pm 12.85)$ with different heights are placed around the style and the annular nectary located at its base. The flowers did not reflect UV and all their parts are white, except for the orange base of the filaments, which contrasts with the tepals (Fig. 1B-C). The length of the style-stigma was 0.79 
$\pm 0.07 \mathrm{~cm}$, so that the lobed stigma was positioned above the stamens (i.e., approach herkogamy, Fig. 1C). Each flower produced $71.08 \pm 13.79$ ovules. Anthesis started at about 8.00 AM, with the outer tepals opening first, followed by the inner tepals. The stamens were initially bent toward the center, so the introrse anthers leaned on the style. With the advance of anthesis they acquired the erect position. The opening of the flowers was completed around 9.00 AM, and they closed at around 4.00 PM. Flowers are nyctinastic and the dynamics of opening and closing occurred in the same way on the second day of anthesis, which marked the end of anthesis.

The flowers already contained nectar at the beginning of anthesis ( 14 of 15 flowers sampled), although the production was small. In the first measurement at $9.00 \mathrm{AM}, 0.67 \pm$ $0.33 \mu \mathrm{L}$ of nectar had accumulated, with a concentration of $26.82 \pm 14.11 \%$. Nectar secretion ceased after the first withdrawal in $87 \%$ of the samples (13 flowers). The two flowers that secreted after withdrawal accumulated $0.8 \mu \mathrm{L}$ and $0.1 \mu \mathrm{L}$ of nectar (second measurement at 3.00 PM). No flower secreted nectar on the second day of anthesis.

\section{Reproductive system}

Rhipsalis neves-armondii is self-sterile and obligate xenogamous since fruit set and seed number were negligible after self-pollinations. The only fruit that was set after spontaneous self-pollination did not have seeds, and the three fruits that were set after the manual self-pollinations produced only a single seed among them (Tab. 1). The number of fruits differed significantly among treatments $\left(X^{2}=87.31 ; \mathrm{df}=3 ; \mathrm{N}=97 ; \mathrm{p}<0.001\right.$; variance random effect $=7.62, \mathrm{SD}=2.76)$. The number of seeds per fruit did not differ between the cross-pollination treatments and the natural conditions $\left(X^{2}=0.0002 ; \mathrm{df}=1 ; \mathrm{N}=42 ; \mathrm{p}>0.05\right.$; variance random effect $=1.71$. $S D=1.31$ ) so no pollen limitation was detected (ILP $=-0.22)($ Tab. 1$)$.

\section{Flower visitors}

Female bees belonging to 14 species of three families (Andrenidae, Apidae and Halictidae) were responsible for almost all visits to flowers (98.2\%). In addition to the bees, only one unidentified species of wasp and one fly visited the flowers, each of them once and without making contact with the stigma (i.e., ineffective visitors). A half of bee species did not contact the stigma region during their visits either, and some of other species performed both efficacious and inefficacious visits (Tab. 2). Rhophitulus solani (24\%), Apis mellifera (23\%), Trigona braueri (15\%) and $T$. spinipes (14\%) were the most frequent visitors (Tab. 2) and possibly the most effective pollinators (sensu

Table 1. Fruit set and mean number of seeds per fruit for hand pollination treatments in flowers of Rhipsalis neves-armondii.

\begin{tabular}{|c|c|c|c|}
\hline Treatments & Flowers & Fruit set (\%) & $\begin{array}{c}\text { Seed number } \\
\text { (mean } \pm \text { SE) }\end{array}$ \\
\hline Spontaneous self-pollination & 30 & $1(3.33)$ & 0 \\
\hline Hand self-pollination & 25 & $3(12.00)$ & 1 \\
\hline Hand cross-pollination & 14 & $11(78.57)$ & $40.12 \pm 19.98$ \\
\hline Natural conditions & 28 & $27(96.43)$ & $35.70 \pm 19.94$ \\
\hline
\end{tabular}

Table 2. Species of floral visitors of Rhipsalis neves-armondii, their absolute and relative frequency of visits (respectively the number of visited flowers / total observation time ( $26 \mathrm{~h}$ ), and the number of visits by the species / total number of visits $\times 100)$. The last column shows the proportion of visits that resulted in contact of the visitor with the anthers and the stigma (efficacious visits). Frequency values represent pooled efficacious and inefficacious visits by floral visitors.

\begin{tabular}{|c|c|c|c|}
\hline Species & Absolute frequency & Relative frequency (\%) & Stigma contact rate \\
\hline Rhophitulus solani Ducke, 1912 & 1.03 & 23.95 & 0.96 \\
\hline Apis mellifera Linnaeus, 1758 & 1.00 & 23.26 & 1.00 \\
\hline Trigona braueri Friese, 1900 & 0.65 & 15.12 & 1.00 \\
\hline Trigona spinipes Fabricius, 1793 & 0.61 & 14.19 & 1.00 \\
\hline Dialictus sp. 1 & 0.38 & 8.84 & 1.00 \\
\hline Ceratina sp. 1 & 0.19 & 4.42 & 0.40 \\
\hline Plebeia droryana Friese, 1900 & 0.08 & 1.86 & 0.00 \\
\hline Partamona helleri Friese, 1900 & 0.04 & 0.93 & 1.00 \\
\hline Augochlorini & 0.04 & 0.93 & 1.00 \\
\hline Augochlorella sp. 1 & 0.04 & 0.93 & 1.00 \\
\hline Augochlorella sp. 2 & 0.04 & 0.93 & 0.00 \\
\hline Dialictus sp. 2 & 0.04 & 0.93 & 0.00 \\
\hline Ceratina sp. 2 & 0.04 & 0.93 & 0.00 \\
\hline Osirini & 0.04 & 0.93 & 1.00 \\
\hline Diptera & 0.04 & 0.93 & 0.00 \\
\hline Vespidae & 0.04 & 0.93 & 0.00 \\
\hline Total & 4.3 & 100 & \\
\hline
\end{tabular}


Freitas 2013). Individuals of $R$. solani searched for pollen and nectar, and the large majority ( $96 \%$ ) of their visits were efficacious (Fig. 1E-F, Tab. 2). Those bees frequently used the stigma as a landing platform, and then moved among the stamens looking for pollen on the anthers (Fig. 1E). They also used the style to move toward the base of the flower where nectar accumulated (Fig. 1F). Individuals of A. mellifera harvested only pollen. They used different parts of the flower for landing and holding (tepals, stamens and stigma) and contacted the stigma in all visits, due to their size. Trigona braueri and T. spinipes were highly effective visitors and behaved similarly to A. mellifera, although they also searched for nectar. The other species made less than $10 \%$ of the visits, most of them inefficacious (Tab. 2). Inefficacious visits mostly reflected "lateral approaches" by small visitors, when they used tepals for landing and hence made no contact with the stigma above.

\section{Discussion}

Rhipsalis neves-armondii was visited by species of different functional groups, belonging to three orders of insects. This broad spectrum of floral visitors suggests a functional generalist pollination system (sensu Ollerton et al. 2007). However, the visiting frequencies of visitors do not support this idea. Only three species of small native bees and A. mellifera touch stigma/anthers and showed high frequencies of visits to the flowers, an indicative of pollination effectiveness (sensu Freitas 2013). Thus, pollination of this species of cactus actually relied on a few bee species, indicating a pollination system with both ecological and functional-group specialization (Ollerton et al. 2007; Armbruster 2017). These finds did not corroborate the generalist pollination system we predicted based on its small open radial flowers that offer exposed nectar and pollen. Flowers with this phenotype are typically classified as generalists, based on the assumption that their pollen and nectar are easily accessible and can be collected by a wide range of flower visitors (e.g. Frame 2003). However, easy access to resources does not necessarily correspond to the occurrence of pollination by diverse groups. In polystemous flowers with radial symmetry, in which the anthers are positioned below the stigma (similarly to "papavertype pollen flowers" sensu Vogel 1978), the pollination effectiveness of floral visitors depends on their size and their foraging behavior. Accordingly, degrees of specialization and mechanism of pollination (specifically the use of the stigma as a landing platform) equivalent to those observed in $R$. neves-armondii have been recorded for other species with similar flowers (e.g. Hypericum roeperianum and $H$. revolutum, Bartoš et al. 2015). These results indicate that the absence of clear morphological barriers to access floral resources may not be a universal indicator of phenotypic generalization (Ramirez 1989; Freitas \& Sazima 2006), particularly in flowers in which the pollination mechanism requires specific behaviors of floral visitors.
Functionally or even ecologically specialized pollination systems involving flowers considered as "typically generalist" have been previously recorded in species of several families (e.g. Lindsey \& Bell 1985; Ramirez 1989; Freitas \& Sazima 2006; Ollerton et al. 2007; Shuttleworth \& Johnson 2009; Narbona \& Dirzo 2010; Niemirski \& Zych 2011; Bartoš et al. 2015), including Cactaceae (species of Ferocactos, McIntosh 2005; as well as others Rhipsalis, C Martins unpubl. res.). In the case of Ferocactus, pollination is restricted to a small number of oligolectic bees that are closely associated with Cactaceae (Diadasia rinconis, Svastra duplocincta and Ashmeadiella opuntiae). In this system, more than $90 \%$ of the seeds produced by two species (F. cylindraceus and F. wislizeni) resulted from visits by those bees (McIntosh 2005). Other well-documented cases deal with species of Apiaceae (Lindsey \& Bell 1985; Niemirski \& Zych 2011). In Angelica sylvestris only a small group of flies contributed to pollination, although more than 70 species visited the flowers (Niemirski \& Zych 2011). Similarly, Thaspium and Zizia species were pollinated only by an oligolectic solitary bee (Andrena ziziae), which led to the proposal of the concept of a pollination system with "cryptic specialization" (Lindsey \& Bell 1985). This term refers to systems in which small changes in floral structure and physiology have the result that only a few among the broad spectrum of floral visitors are effective in pollination (Lindsey \& Bell 1985). Similar reasoning could be applied to $R$. neves-armondii, in which non-specific attributes of floral morphology may be filtering the interaction with pollinators. For instance, characteristics of nectar such as volume and concentration are often correlated with certain pollinator groups, and this relationship is based mainly on their body size and energy requirements (Brown et al. 1978). The small amount of nectar in R. neves-armondii may therefore constitute a filter for certain pollinators-floral visitors with a high energy demand (Ollerton et al. 2007). However, this would not explain the small number of visitors, considering the diverse local fauna of small insects with supposed low energy and/ or pollen demands, so that other attributes involved with floral attraction and repulsion, such as odors, may be acting. In short, the flowers of $R$. neves-armondii seem to have nonmorphological filters (e.g. Shuttleworth \& Johnson 2009) that restrict the access of certain visitors to their resources, although the present data do not allow us to explore this question more deeply.

The bee $R$. solani was the most frequent pollinator in $R$. neves-armondii. Species of this genus, as well as members of Andrenidae as a whole, are usually oligolectic, i.e., bees that collect pollen in a small number of often related plants (Linsley 1958; Cane \& Sipes 2006). This seems to be the case of Rhophitulus, since species of this genus were the most frequent visitors of other Cactaceae species in the PARNASO (R. teres and Hatiora salicornioides) and in other areas of the Atlantic Forest (R. pentaptera) but were not prominent in a community-level inventory in the PARNASO (L Freitas et al. unpubl. res.). This bee species uses the stigma of $R$. neves- 
armondii as a landing platform and then moves toward the anthers and nectary. The approach herkogamy of $R$. nevesarmondii flowers, together with the behavior of $R$. solani during the visits to the flowers possibly favor the deposition of cross-pollen on the stigma, as it is the first structure touched by the bee. Moreover, oligolectic bees transport less-heterogeneous pollen loads (Linsley 1958; Cane \& Sipes 2006), which should lead to low deposition of interspecific pollen on the stigma, and the occurrence of oligolectic bees with high pollination effectiveness is common in Cactaceae (e.g. Mandujano et al. 1996; Schlindwein \& Wittmann 1997). Mechanisms of pollination that favors cross-pollination are usually invoked as the result of selection to reduce selfpollination, due to the deleterious effects of inbreeding (see Busch 2005). However, since $R$. neves-armondii is highly selfsterile, probably due to self-incompatibility mechanism yet to be studied in detail, inbreeding is mostly restricted and pollination mechanism probably is related to the avoidance of interference between pollen presentation and stigma receptivity (Webb \& Lloyd 1986; Narbona et al. 2011).

The other most-frequent bee species in the flowers of $R$. neves-armondii were A. mellifera, T. spinipes and T. braueri, which are highly generalist species, with numerous records reporting visits to a large number of species belonging to several pollination syndromes (e.g. Linsley 1958; CortopassiLaurino \& Ramalho 1988). These bees collect pollen with high efficiency, storing large amounts in their corbicula. Visits by those three species to $R$. neves-armondii flowers always resulted in contact with the stigma and the anthers, reflecting the size of the bees and their movements within the flowers during pollen collection.

Rhipsalis neves-armondii is a mandatory xenogamous species, since self crosses result in a high abortion rate of fruits and seeds. Many species of Cactaceae with different pollination systems are dependent on pollinators for sexual reproduction (reviewed by Ross 1981; Boyle 1997; 2003; Pimienta-Barrios \& Castillo 2002; Mandujano et al. 2010). However, a few studies have examined selfsterility mechanisms in this family, so failures of fruit and seed production after selfing could reflect either strong inbreeding depression or self-incompatibility (Mandujano et al. 2010). Some species of Schlumbergera and Hatiora are among the taxa with a genetically controlled selfincompatibility mechanism, specifically a gametophytic system controlled by a multi-allelic locus (Boyle 1997; 2003). These two genera belong to Rhipsalideae, together with Rhipsalis and Lespismium (Calvente et al. 2011a), so futher studies may define if the self-sterility in Rhipsalis nevesarmondii is due to a similar self-incompatibility system.

In conclusion, the pollination system of $R$. neves-armondii population in the PARNASO can be characterized as specialized from the plant's perspective, because only a few small bees among dozens of anthophilous insects in the area visited its flowers effectively. However, from a zoocentric perspective these bees belong to distinct functional groups, from possibly oligolectic $R$. solani to super-generalist $A$. mellifera. Behavioral differences, such as those involving the use of floral resources by bees, can lead to distinct selective pressures on flowers (see Armbruster 2017), even among taxonomically related species of pollinators and/or among species that belong to the same classical functional groups.

\section{Acknowledgements}

We thank Clemens Schlindwein, Maria Cristina Gaglianone e Paula Netto for insect identification; Daniela C. Zappi and Diego R. Gonzaga for discussions on Cactaceae taxonomy; Janet Reid for language revision; the Coordenação de Aperfeiçoamento de Pessoal de Nível Superior (CAPES) for awarding a PhD scholarship to C.M.; the Conselho Nacional de Desenvolvimento Científico e Tecnológico (CNPq) for a PQ scholarship to L.F. and for funding the project (PVE 400789/2014-0); and PARNASOICMBio for permission to carry out the study.

\section{References}

Anderson B, Terblanche J, Ellis A. 2010. Predictable patterns of trait mismatches between interacting plants and insects. BMC Evolutionary Biology 10: 204.

Anderson EF. 2001. The cactus family. Portland, Timber Press.

Armbruster WS. 1993. Evolution of plant pollination systems: hypotheses and tests with the neotropical vine Dalechampia. Evolution 47: 14801505.

Armbruster WS. 2017. The specialization continuum in pollination systems: diversity of concepts and implications for ecology, evolution and conservation. Functional Ecology 31: 88-100.

Barthlott W. 1983. Biogeography and evolution in neo-and paleotropical Rhipsalinae (Cactaceae). Naturwissenschaftlichen Vereins Hamburg 7: 241-248.

Bartoš M, Tropek R, Spitzer L, et al. 2015. Specialization of pollination systems of two co-flowering phenotypically generalized Hypericum species (Hypericaceae) in Cameroon. Arthropod-Plant Interactions 9: 241-252.

Boyle TH. 1997. The genetics of self-incompatibility in the genus Schlumbergera (Cactaceae). Journal of Heredity 88: 209-214.

Boyle TH. 2003. Identification of self-incompatibility groups in Hatiora and Schlumbergera (Cactaceae). Sexual Plant Reproduction 16: 151-155.

Brown JH, Calder WA, Kodric-Brown A. 1978. Correlates and consequences of body size in nectar-feeding birds. American Zoologist 18: 687-700.

Busch JW. 2005. Inbreeding depression in self-incompatible and selfcompatible populations of Leavenworthia alabamica. Heredity 94: 159-165.

Calvente A. 2012. A new subgeneric classification of Rhipsalis (Cactoideae, Cactaceae). Systematic Botany 37: 983-988.

Calvente A, Freitas MF, Andreata RHP. 2005. Listagem, distribuição geográfica e conservação das espécies de Cactaceae no Estado do Rio de Janeiro. Rodriguésia 56: 141-162.

Calvente A, Zappi DC, Forest F, Lohmann LG. 2011a. Molecular phylogeny of tribe Rhipsalideae (Cactaceae) and taxonomic implications for Schlumbergera and Hatiora. Molecular Phylogenetics and Evolution 58: 456-468.

Calvente A, Zappi DC, Forest F, Lohmann LG. 2011b. Molecular phylogeny, evolution, and biogeography of South American epiphytic cacti. International Journal of Plant Sciences 172: 902-914.

Cane JH, Sipes S. 2006. Characterizing floral specialization by bees: analytical methods e-revised lexicon for oligolecty. In: Waser NM, Ollerton J. (eds.) Plant-pollination interactions: from specialization to generalization. Chicago, The University of Chicago Press. p. 99-121. 
Cortopassi-Laurino M, Ramalho M. 1988. Pollen harvest by Africanized Apis mellifera and Trigona spinipes in São Paulo - botanical and ecological views. Apidologie 19: 1-24.

Faegri K, Pijl L. 1979. The principles of pollination ecology. 3rd. edn. New York, Pergamon Press.

Fleming TH, Geiselman C, Kress WJ. 2009. The evolution of bat pollination: a phylogenetic perspective. Annals of Botany 104: 1017-1043.

Frame D. 2003. Generalist flowers, biodiversity and florivory: implications for angiosperm origins. Taxon 52: 681-685.

Freitas L. 2013. Concepts of pollinator performance: is a simple approach necessary to achieve a standardized terminology? Brazilian Journal of Botany 36: 3-8.

Freitas L, Andrich M. 2013. Is the pollination biology of Bathysa and Schizocalyx consistent with their segregation? A first approach for two sympatric species in southeastern Brazil. Journal of Systematics and Evolution 51: 522-535.

Freitas L, Sazima M. 2006. Pollination biology in a tropical high-altitude grassland in Brazil: Interactions at the community level. Annals of the Missouri Botanical Garden 93: 465-516.

Gómez JM, Muñoz-Pajares AJ, Abdelaziz M, Lorite J, Perfectti F. 2014. Evolution of pollination niches and floral divergence in the generalist plant Erysimum mediohispanicum. Annals of Botany 113: 237-249.

Grant V, Grant KA. 1965. Flower pollination in the Phlox family. New York, Columbia University Press.

Hunt D, Taylor N, Charles G. 2006. The new cactus lexicon: descriptions and illustrations of the cactus family. Vols. I and II. Milborne Port/ Dorset, David Hunt Books.

Johnson SD, Steiner KE. 2000. Generalization versus specialization in plant pollination systems. Trends in Ecology \& Evolution 15: 140-143.

King C, Ballantyne G, Willmer PG. 2013. Why flower visitation is a poor proxy for pollination: measuring single-visit pollen deposition, with implications for pollination networks and conservation. Methods in Ecology and Evolution 4: 811-818.

Köppen W. 1936. Das geographische System der Klimate. In: Köppen W, Geiger R. (eds.) Handbuch der Klimatologie. Vol 1-C. Berlin, Gebrüder Bornträger. p. 1-44.

Larson BMH, Barrett SCH. 2000. A comparative analysis of pollen limitation in flowering plants. Biological Journal of the Linnean Society 69: 503-520.

Lindsey AH, Bell CR. 1985. Reproductive biology of Apiaceae. II. Cryptic specialization and floral evolution in Thaspium and Zizia. American Journal of Botany 72: 231-247.

Linsley EG. 1958. The ecology of solitary bees. Hilgardia 27: 543-599.

Mandujano MDC, Carrillo-Angeles IG, Martínez-Peralta C, Golubov J. 2010. Reproductive biology of Cactaceae. In: Ramawat KG. (ed.) Desert plants: biology and biotechnology. Berlin/ Heidelberg, SpringerVerlag. p. 197-230.

Mandujano MDC, Montana C, Eguiarte LE. 1996. Reproductive ecology and inbreeding depression in Opuntia rastrera (Cactaceae) in the Chihuahuan desert: why are sexually derived recruitments so rare? American Journal of Botany 83: 63-70.

McIntosh ME. 2005. Pollination of two species of Ferocactus: interactions between cactus-specialist bees and their host plants. Functional Ecology 19: 727-734.

Narbona E, Dirzo R. 2010. A reassessment of the function of floral nectar in Croton suberosus (Euphorbiaceae): A reward for plant defenders and pollinators. American Journal of Botany 97: 672-679.

Narbona E, Ortiz PL, Arista M. 2011. Linking self-incompatibility, dichogamy, and flowering synchrony in two Euphorbia species: alternative mechanisms for avoiding self-fertilization? Plos One 6: e20668. doi: 10.1371/journal.pone.0020668
Ne'eman G, Jürgens A, Newstrom-Lloyd L, Potts SG, Dafni A. 2010. A framework for comparing pollinator performance: effectiveness and efficiency. Biological Reviews 85: 435-451.

Nicolson SW, Wright GA. 2017. Plant-pollinator interactions and threats to pollination: perspectives from the flower to the landscape. Functional Ecology 31: 22-25.

Niemirski R, Zych M. 2011. Fly pollination of dichogamous Angelica sylvestris (Apiaceae): how (functionally) specialized can a (morphologically) generalized plant be? Plant Systematics and Evolution 294: 147-158.

Ollerton J. 2006. "Biological barter": patterns of specialization compared across different mutualisms. In: Waser NM, Ollerton J. (eds.) Plantpollination interactions: from specialization to generalization. Chicago, The University of Chicago Press. p. 411-435.

Ollerton J, Killick A, Lamborn E, Watts S, Whiston M. 2007. Multiple meanings and modes: on the many ways to be a generalist flower. Taxon 56: 717-728.

Pimienta-Barrios E, Castillo RF. 2002. Reproductive biology. In: Nobel PS. (ed.) Cacti: biology and uses. Berkeley, University of California Press. p. 75-90.

Ramirez N. 1989. Biologia de polinización en una comunidad arbustiva tropical de la alta Guayana Venezolana. Biotropica 21: 319-330.

Ross R. 1981. Chromosome counts, cytology, and reproduction in the Cactaceae. American Journal of Botany 68: 463-470.

Sargent RD, Ackerly DD. 2008. Plant-pollinator interactions and the assembly of plant communities. Trends in Ecology \& Evolution 23: 123-130

Schlindwein C, Wittmann D. 1997. Stamen movements in flowers of Opuntia (Cactaceae) favour oligolectic pollinators. Plant Systematics and Evolution 204: 179-193.

Schlumpberger BO. 2012. A survey on pollination modes in cacti and a potential key innovation. In: Patiny S. (ed.) Evolution of plantpollinator relationships. Cambridge, Cambridge University Press. p. 301-321.

Schlumpberger BO, Clery RA, Barthlott W. 2006. A unique cactus with scented and possibly bat-dispersed fruits: Rhipsalis juengeri. Plant Biology 8: 265-270.

Shuttleworth A, Johnson SD. 2009. The importance of scent and nectar filters in a specialized wasp-pollination system. Functional Ecology 23: 931-940.

Stebbins GL. 1970. Adaptive radiation of reproductive characteristics in angiosperms, I: pollination mechanisms. Annual Review of Ecology and Systematics 1: 307-326.

Taylor N, Santos MR, Larocca J, Zappi D. 2015. Cactaceae In: Lista de Espécies da Flora do Brasil. http://floradobrasil.jbrj.gov.br/jabot/ floradobrasil/FB1681. 15 Apr. 2017.

Thomson JD, Wilson P. 2008. Explaining evolutionary shifts between bee and hummingbird pollination: convergence, divergence, and directionality. International Journal of Plant Sciences 169: 23-38.

Tschapka M, Helversen O, Barthlott W. 1999. Bat pollination of Weberocereus tunilla, an epiphytic rain forest cactus with functional flagelliflory. Plant Biology 1: 554-559.

Vogel ST. 1978. Evolutionary shifts from reward to deception in pollen flowers. In: Richards AJ. (ed.) The pollination of flowers by insects. Vol. 6. London, Linnean Society Symposium. p. 89-96.

Waser NM, Chittka L, Price MV, Williams NM, Ollerton J. 1996. Generalization in pollination systems, and why it matters. Ecology 77: 1043-1060.

Webb CJ, Lloyd DG. 1986. The avoidance of interference between the presentation of pollen and stigmas in angiosperms II. Herkogamy. New Zealand Journal of Botany 24: 163-178. 